\title{
Importância da intoxicação por Amorimia pubiflora (Malpighiaceae) em bovinos em Mato Grosso: reprodução experimental da intoxicação em ovinos e bovinos ${ }^{1}$
}

\author{
Marciel Becker², Flávio Henrique Bravin Caldeira², Faber Monteiro Carneiro², \\ Leonardo Pintar de Oliveira ${ }^{3}$, Carlos Hubinger Tokarnia ${ }^{4}$, Franklin Riet-Correa ${ }^{5}$, \\ Stephen T. Lee ${ }^{6}$ e Edson Moleta Colodel ${ }^{7 *}$
}

\begin{abstract}
Becker M., Caldeira F.H.B., Carneiro F.M., Oliveira L.P., Tokarnia C.H., Riet-Correa F., Lee S.T. \& Colodel E.M. 2013. [The importance of poisoning by Amorimia pubiflora (Malpighiaceae) in cattle in Mato Grosso: experimental reproduction of the poisoning in sheep and cattle.] Importância da intoxicação por Amorimia pubiflora (Malpighiaceae) em bovinos em Mato Grosso: reprodução experimental da intoxicação em ovinos e bovinos. Pesquisa Veterinária Brasileira 33(9):1049-1056. Departamento de Clínica Médica Veterinária, Faculdade de Agronomia, Medicina Veterinária e Zootecnia, Universidade Federal de Mato Grosso, Av. Fernando Corrêa da Costa 2367, Cuiabá, MT 78068-900, Brazil. Email: moleta@ufmt.br

In the county of Colniza, Mato Grosso, the main limitation for livestock production is the occurrence of "sudden death" in cattle, which affects in some farms up to $50 \%$ of the herd. In visits to some of the farms where the problem occurred, in 2004, 2011 and 2012, the presence of Amorimia pubiflora on the pastures was associated with the occurrence of "sudden deaths" in cattle. The deaths occurred throughout the year, however more frequently at beginning of the rainy season, when A. pubiflora sprouts in the grazing areas. The poisoning was experimentally reproduced in sheep and cattle by the administration of young leaves of the plant collected during two seasons, and in sheep by the administration of mature leaves and fruits. In the sheep that died, the first clinical signs were observed between $34 \mathrm{~min}$ and $17 \mathrm{~h} 34 \mathrm{~min}$ after the administration of the plant, and the clinical course varied from $3 \mathrm{~min}$ to $15 \mathrm{~h} 20 \mathrm{~min}$, with a final peracute phase of 3 to 21 minutes. The main clinical signs were tachycardia, engorgement of the jugular veins, muscle trembling, apathy and reluctance to move, which were more evident when the animals were moved. The peracute final phase was characterized by generalized tremors and muscle contractions mainly of limbs, head and neck, respiratory distress and abdominal respiration, sternal and quick lateral recumbence or falling to the ground with peddling movements, opisthotonus, nystagmus, nystagmus and cyanosis of the oral mucosa, followed by death. The young leaves of $A$. pubiflora, independent of the collection period, were more toxic and caused death of sheep and cattle after ingestion of $2 \mathrm{~g} / \mathrm{kg}$ and $3 \mathrm{~g} / \mathrm{kg}$ respectively. Mature leaves caused death at the dose of $20 \mathrm{~g} / \mathrm{kg}$, and the fruits at $5 \mathrm{~g} / \mathrm{kg}$. The young leaves contained $0.015 \%$
\end{abstract}

\footnotetext{
${ }^{1}$ Recebido em 25 de março de 2013.

Aceito para publicação em 18 de abril, de 2013.

Parte da Dissertação de Mestrado do primeiro autor, defendida na Universidade Federal de Mato Grosso (UFMT), Cuiabá, MT, Brasil.

${ }^{2}$ Pós-Graduando em Ciências Veterinárias, Faculdade de Agronomia e Medicina Veterinária, UFMT, Av. Fernando Corrêa da Costa 2367, Cuiabá, MT 78068-900.

${ }^{3}$ Graduando em Medicina Veterinária, Faculdade de Agronomia e Medicina Veterinária, UFMT, Cuiabá, MT. Bolsista da Fundação de Amparo à Pesquisa do Estado de Mato Grosso (FAPEMAT).

${ }^{4}$ Departamento de Nutrição Animal e Pastagem, Instituto de Zootec-
}

\footnotetext{
nia, Universidade Federal Rural do Rio de Janeiro (UFRRJ), Seropédica, RJ 23835-000, Brasil.

${ }^{5}$ Hospital Veterinário, Centro de Saúde e Tecnologia Rural (CSTR), Universidade Federal de Campina Grande (FCG), Campus de Patos, Patos, PB 58700-000, Brasil

${ }^{6}$ Poisonous Plant Research Laboratory, Agricultural Research Service, United States Department of Agriculture, 1150 E. 1400 N., Logan, UT 84341, USA

${ }^{7}$ Departamento de Clínica Médica Veterinária, Faculdade de Agronomia e Medicina Veterinária, UFMT, Cuiabá, MT. *Autor para correspondência: moleta@ufmt.br
} 
of sodium monofluoracetate which is responsible for clinical signs of the "sudden death". These findings show the importance of Amorimia pubiflora for cattle raising in Midwestern Brazil. The plant is toxic also for sheep causing a clinical picture similar to that reported in cattle poisoned by monofluoracetate-containing plants.

INDEX TERMS: Poisonous plants, Amorimia pubiflora, Mascagnia pubiflora, Malpighiaceae, monofluoracetate, plant poisoning, sudden death, cattle, sheep.

RESUMO.- No município de Colniza, Mato Grosso, a principal limitação para expansão pecuária é a ocorrência de "morte súbita" em bovinos, com registros de mortalidade próxima a $50 \%$ dos animais. Em visitas realizadas em áreas de ocorrência do problema, nos anos de 2004, 2011 e 2012, constatou-se que havia coincidência entre a ocorrência de "mortes súbitas" no rebanho e a presença de Amorimia pubiflora nas pastagens. As mortes ocorrem durante todo ano, porém acentuam-se no início do período das chuvas, quando há maior quantidade de brotação nas áreas de pastoreio. A intoxicação foi reproduzida em ovinos e bovinos através da administração de folhas jovens coletadas em dois períodos do ano, e, em ovinos, através de folhas maduras e dos frutos. Nos ovinos que morreram, as primeiras manifestações clínicas foram observadas entre $34 \mathrm{~min}$ e 17h34min após a administração da planta e a evolução clínica foi de $3 \mathrm{~min}$ a $15 \mathrm{~h} 20 \mathrm{~min}$, com uma fase final superaguda de 3 a $21 \mathrm{~min}$. As principais alterações clínicas encontradas foram taquicardia, evidenciação da jugular, tremores musculares, apatia e relutância à movimentação. Todos os sinais acentuavam-se após a movimentação. A fase final superaguda foi caracterizada por relutância para caminhar, cifose, tremores e contrações musculares generalizadas, principalmente de membros, cabeça e pescoço. Notou-se também taquipneia com respiração abdominal, decúbito esternal e rapidamente lateral ou quedas em decúbito lateral, opistótono, nistagmo e cianose de mucosa oral, seguidos de morte. As folhas jovens, independentemente do período da coleta, foram mais tóxicas; causaram a morte de ovinos a partir de $2 \mathrm{~g} / \mathrm{kg}$ e de um bovino que ingeriu $3 \mathrm{~g} /$ $\mathrm{kg}$. Já as folhas maduras revelaram-se tóxicas e causaram morte na dose de $20 \mathrm{~g} / \mathrm{kg}$ e os frutos ocasionaram a morte de um ovino que ingeriu $5 \mathrm{~g} / \mathrm{kg}$. Concluímos que monofluoracetato de sódio (MFA), encontrado na concentração de $0,015 \%$ nas folhas em brotação de A. pubiflora, é o princípio tóxico responsável pela "morte súbita" causada por Amorimia pubiflora. Esse estudo mostra a importância de A. pubiflora para a região Centro-Oeste do Brasil, principalmente para a pecuária bovina do município de Colniza, MT. Essa planta é tóxica, também, para ovinos e o quadro clínico é similar ao descrito para bovinos.

TERMOS DE INDEXAÇÃO: Plantas tóxicas, Amorimia (Mascagnia) pubiflora, Malpighiaceae, monofluoracetato, intoxicação por plantas, "morte súbita", bovinos, ovinos.

\section{INTRODUÇÃO}

Quadros clínicos de "morte súbita" associados ao consumo de plantas tóxicas estão entre as principais causas de perdas econômicas na pecuária bovina brasileira. As plantas responsáveis por este quadro clínico pertencem às famílias Rubiaceae, Bignoniaceae e Malpighiaceae. Na última família, as espécies do gênero Mascagnia (Tokarnia et al. 2012), atualmente reclassificadas como Amorimia (Anderson 2006), são encontradas em todas as regiões do Brasil (Mamede 2010).

Amorimia pubiflora (A. Juss.) W.R. Anderson (anteriormente Mascagnia pubiflora) (Anderson 2006), conhecida popularmente como "corona" e "cipó-prata" (Tokarnia \& Döbereiner 1973, Tokarnia et al. 2012), é uma das plantas tóxicas para bovinos mais importantes da região Centro-Oeste e áreas vizinhas da região Sudeste (Tokarnia \& Döbereiner 1973).

Em Mato Grosso do Sul, A. pubiflora foi responsável por vários surtos de "mortes súbitas" em diferentes meses do ano, mas os casos predominaram no período chuvoso com morbidade de até 3,5\%; as mortes frequentemente são relacionadas com a movimentação (Lemos et al. 2011). Foram descritas variações na toxidez das folhas de acordo com a época do ano, enquanto em agosto/setembro, na época da seca, com A. pubiflora em brotação, floração e frutificação, a dose letal das folhas frescas foi de $5 \mathrm{~g} / \mathrm{kg}$, em abril/maio do mesmo ano, no final da época de chuva, com as folhas maduras, ela situou-se em torno de $20 \mathrm{~g} / \mathrm{kg}$ (Tokarnia \& Döbereiner 1973).

Bovinos intoxicados por A. pubiflora apresentaram, quando movimentados, cansaço, jugular ingurgitada, leves tremores musculares, contrações bruscas e morte no período de 5 a 15 minutos (Tokarnia \& Döbereiner 1973). Na necropsia não houve lesões significativas, porém histologicamente no rim notou-se, em aproximadamente metade dos bovinos intoxicados, degeneração hidrópico-vacuolar acompanhada de cariopicnose no epitélio dos túbulos contornados distais, o que é um achado importante para o diagnóstico (Tokarnia et al. 2012). Alteração similar foi reproduzida em bovinos (Nogueira et al. 2010) e ovinos (Peixoto et al. 2010), com a administração de monofluoracetato de sódio (MFA) (Nogueira et al. 2010, Peixoto et al. 2010). Nesta espécie e em A. amazonica, A. camporum, $A$. exotropica, A. rigida e A. septentrionalis, foi detectado MFA (Lee et al. 2012).

Este trabalho tem o objetivo de descrever os aspectos epidemiológicos da intoxicação natural por $A$. pubiflora em bovinos no estado de Mato Grosso e a reprodução experimental da intoxicação em ovinos e bovinos com a brotação da planta coletada na região Centro-Oeste nos períodos de chuvas e de seca e da planta madura e os frutos na época de seca.

\section{MATERIAL E MÉTODOS}

O estudo foi aprovado pelo Comitê de Ética em Pesquisa Animal da Universidade Federal de Mato Grosso (UFMT), através do processo número 23108.014901/11-7 de 13 de maio de 2011. Foram coletadas separadamente folhas jovens (tenras e predominante- 


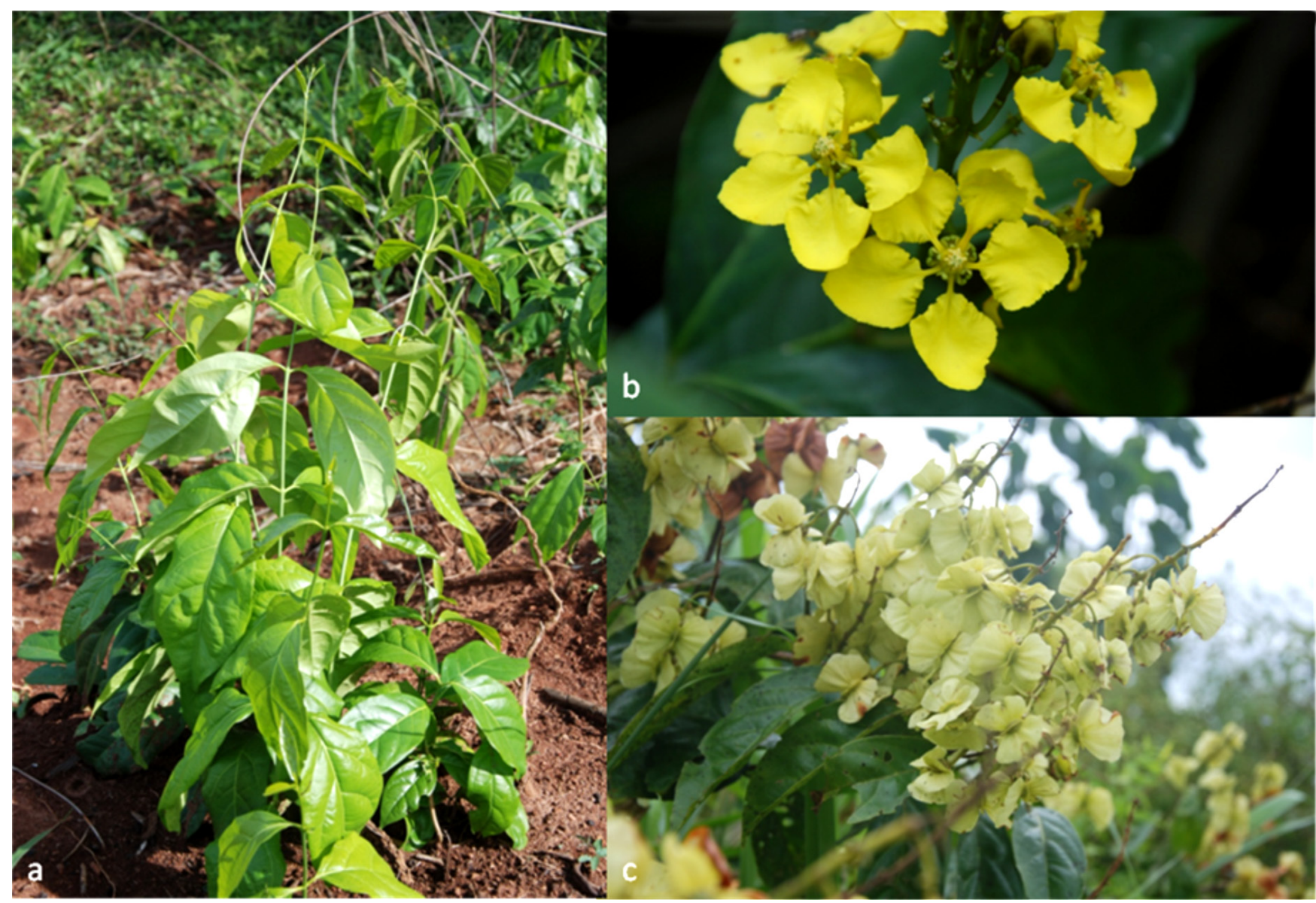

Fig.1. Amorimia pubiflora, julho de 2012, Colniza, MT. (a) Brotação, (b) inflorescência, (c) frutos.

mente verde-claras tanto na face dorsal quanto ventral, ligadas a talos verdes), folhas maduras (verde-escuras, fibrosas) e frutos de Amorimia pubiflora, em uma Fazenda no município de Colni$\mathrm{za}, \mathrm{MT}$, em um raio de aproximadamente $5 \mathrm{~km}$ de $509^{\circ} 41.879$ -W059 06.544) nos dias 14.11.2011, 19.12.2011 e 08.06.2012 (Fig.1). As duas primeiras coletas ocorreram nos períodos de chuvas e a terceira ocorreu no período de seca. As folhas e frutos foram conservados sob refrigeração, a $4-8^{\circ} \mathrm{C}$ por um período máximo de 30 dias, para utilização neste experimento.

A identificação botânica foi realizada pelo Dr. William R. Anderson (University of Michigan Herbarium, Ann Arbor, Michigan, EUA). Folhas de A. pubiflora foram enviadas ao Toxic Plant Laboratory, Agricultural Research Service, United States Department of Agriculture, Logan, UT, USA, para verificação da existência de MFA em sua composição, conforme metodologia descrita por Lee et al. (2012).

Investigação epidemiológica. Realizaram-se visitas a diversas propriedades do município de Colniza, MT, em setembro de 2004, novembro de 2011 e julho de 2012 com o fim de coletar informações referentes às "mortes súbitas", mediante a realização de entrevistas com os responsáveis pela criação de bovinos e vistoria das pastagens onde a doença ocorria. Durante a visita em uma das propriedades, um bovino que apresentou quadro de "morte súbita" foi necropsiado e fragmentos dos órgãos das cavidades abdominal, torácica e o encéfalo foram coletados e fixados em solução formalina $10 \%$ tamponada e processados rotineiramente para exame histológico.

Animais experimentais. 0 delineamento dos experimentos em ovinos e as alterações clínicas e lesionais estão dispostas no Quadro 1. Utilizaram-se 18 ovinos oriundos do Projeto Ovinocul- tura, da Fazenda Experimental da UFMT, Santo Antônio de Leverger, MT. Todos eram da raça Santa Inês, fêmeas, com idades entre 1 e 2 anos e estavam clinicamente saudáveis. Os ovinos foram vermifugados entre 7 a 10 dias previamente ao início do experimento. Durante o experimento permaneceram em um piquete no Hospital Veterinário da UFMT, em baias de $9 \mathrm{~m}^{2}$, que comportavam até três ovinos. Todos os ovinos foram pesados no dia da administração da planta para o cálculo da dose administrada.

Utilizaram-se também dois bovinos (Bovinos 1 e 2), que permaneceram em um piquete de $1000 \mathrm{~m}^{2}$, na Fazenda Experimental da UFMT, sendo o Bovino 1, da raça Holandesa, macho, castrado, 24 meses e o Bovino 2, cruza da raça Caracu com Nelore, macho, de 24 meses.

Doses administradas. As folhas de A. pubiflora foram administradas aos animais por via oral. As folhas eram fornecidas inicialmente para serem ingeridas voluntariamente pelos animais. A maioria dos ovinos e os bovinos consumiram as folhas com avidez. Quando isso não acontecia, administravam-se forçadamente pequenos bolos das folhas por via oral. 0 tempo máximo de administração total de folhas para cada ovino e para os bovinos não ultrapassou 25 minutos.

As folhas jovens da primeira e segunda coleta de A. pubiflora (coletadas na época de chuva) foram administradas nas doses de 1,5 (Ovino 23), 2 (Ovinos 50, 22 e 21), 3 (Ovinos 25 e 14) e $5 \mathrm{~g} / \mathrm{kg}$ (Ovinos 20 e 8). Para avaliação da dose tóxica de A. pubiflora, na estação da seca, brotos e folhas jovens foram administrados nas doses de 2 (Ovino 164), 3 (Ovino 163 e 165), 4 (Ovino 156) e 5g/ $\mathrm{kg}$ (Ovino 162 e 17) e as folhas maduras foram administrados nas doses de 10 (Ovino 167), 15 (Ovino 168), e 20g/kg (Ovino166), bem como os frutos de A. pubiflora foram administrados na dose 
Quadro 1. Delineamento experimental, acompanhamento e desfecho clínico e alterações histológicas renais relacionadas com a intoxicação experimental por Amorimia pubiflora em ovinos

\begin{tabular}{|c|c|c|c|c|c|c|c|}
\hline $\begin{array}{l}\text { Ovino } \\
\text { no. }\end{array}$ & Parte administrada & Dose $\mathrm{g} / \mathrm{kg}$ & $\begin{array}{l}\text { Início dos sinais } \\
\text { clínicos }\end{array}$ & $\begin{array}{l}\text { Evolução } \\
\text { clínica }\end{array}$ & $\begin{array}{c}\text { Evolução } \\
\text { fase aguda }\end{array}$ & $\begin{array}{l}\text { Desfecho } \\
\text { clínico }\end{array}$ & $\begin{array}{c}\text { Intensidade das } \\
\text { lesões renais }\end{array}$ \\
\hline 8 & & 5 & $5 \mathrm{~h} 5 \mathrm{~min}$ & $15 \mathrm{~h} 20 \mathrm{~min}$ & $11 \mathrm{~min}$ & Morte & Leve \\
\hline 20 & & 5 & $34 \mathrm{~min}$ & $14 \mathrm{~h} 15 \mathrm{~min}$ & Encontrada morta & Morte & Leve \\
\hline 14 & & 3 & $11 \mathrm{~h} 35 \mathrm{~min}$ & $5 \mathrm{~h} 15 \mathrm{~min}$ & $15 \mathrm{~min}$ & Morte & Ausente \\
\hline 25 & Folhas jovens da & 3 & $8 \mathrm{~h} 15 \mathrm{~min}$ & $17 \mathrm{~h}$ & Encontrada morta & Morte & Leve \\
\hline 22 & $1^{\underline{a}}$ e $2^{\underline{a}}$ coletas & 2 & $13 \mathrm{~h} 04 \mathrm{~min}$ & $3 \mathrm{~h} 40 \mathrm{~min}$ & $4 \mathrm{~min}$ & Morte & Leve \\
\hline 21 & & 2 & $13 \mathrm{~h} 52 \mathrm{~min}$ & $122 \mathrm{~h} 20 \mathrm{~min}$ & N.A. & Recuperação & N.A. \\
\hline 50 & & 2 & $12 \mathrm{~h} 43 \mathrm{~min}$ & $48 \mathrm{~h}$ & N.A. & Recuperação & N.A. \\
\hline 23 & & 1,5 & $6 \mathrm{~h} 57 \min$ & 17h33min & N.A. & Recuperação & N.A. \\
\hline 162 & & 5 & 17h34min & $0 \mathrm{~h} 03 \mathrm{~min}$ & $3 \min 20$ seg & Morte & Leve \\
\hline 17 & & 5 & $14 \mathrm{~h} 04 \mathrm{~min}$ & 0h50min & $6 \mathrm{~min} 30 \mathrm{seg}$ & Morte & Ausente \\
\hline 156 & Folhas jovens da & 4 & $14 \mathrm{~h} 29 \mathrm{~min}$ & $1 \mathrm{~h} 20 \mathrm{~min}$ & $21 \mathrm{~min} 30 \mathrm{seg}$ & Morte & Moderada \\
\hline 163 & $3^{\mathrm{a}}$ coleta & 3 & $14 \mathrm{~h} 45 \mathrm{~min}$ & $6 \mathrm{~h} 45 \mathrm{~min}$ & Encontrada morta & Morte & Ausente \\
\hline 165 & & 3 & $14 \mathrm{~h} 45 \mathrm{~min}$ & $1 \mathrm{~h}$ & Encontrada morta & Morte & Ausente \\
\hline 164 & & 2 & $17 \mathrm{~h} 56$ in & $48 \mathrm{~h} 00 \mathrm{~min}$ & N.A. & Recuperação & N.A. \\
\hline 166 & & 20 & $13 \mathrm{~h} 25 \mathrm{~min}$ & $0 \mathrm{~h} 11 \mathrm{~min}$ & $11 \mathrm{~min} 30 \mathrm{seg}$ & Morte & Moderada \\
\hline 168 & Folhas maduras & 15 & $14 \mathrm{~h} 07 \mathrm{~min}$ & $86 \mathrm{~h} 27 \mathrm{~min}$ & N.A. & Recuperação & N.A. \\
\hline 167 & & 10 & $17 \mathrm{~h} 55 \mathrm{~min}$ & $48 \mathrm{~h} 00 \mathrm{~min}$ & N.A. & Recuperação & N.A. \\
\hline 169 & Frutos & 5 & $15 \mathrm{~h} 45 \mathrm{~min}$ & $2 \mathrm{~h}$ & Encontrada morta & Morte & Leve \\
\hline
\end{tabular}

de $5 \mathrm{~g} / \mathrm{kg}$ (Ovino 169). Folhas jovens de A. pubiflora da primeira coleta foram administradas para os Bovinos 1 e 2, nas doses de 2 e $3 \mathrm{~g} / \mathrm{kg}$, respectivamente. Adicionalmente todos os animais foram alimentados com feno de alfafa e ração comercial específica. Após 6 a 8 horas da administração, os animais foram submetidos à movimentação por 10 minutos.

Acompanhamento clínico da intoxicação experimental. Exames clínicos foram realizados nos ovinos e bovinos previamente à administração da planta e depois com frequência. 0 exame consistia na observação de movimentos respiratórios, comportamento, postura, ingestão de água e alimentos. Durante 3-4 vezes por dia, imediatamente após a movimentação dos animais, eram avaliadas também as frequências cardíaca e respiratória e a movimentação ruminal.

Exames patológicos. Os ovinos e os bovinos que morreram foram necropsiados, anotando-se as alterações macroscópicas. Durante a necropsia, coletaram-se fragmentos de linfonodos, intestino, rúmen, retículo, omaso, abomaso, pâncreas, adrenais, bexiga, rim, tireóide, coração, pulmão, e encéfalo. As amostras foram fixadas em formol a $10 \%$. Após fixação, os fragmentos foram processados no Laboratório de Patologia do Hospital Veterinário da UFMT, incluídos em parafina, cortados em 3-5 $\mu \mathrm{m}$, corados pela hematoxilina e eosina (HE) e avaliados microscopicamente.

\section{RESULTADOS}

\section{Dados epidemiológicos}

O município de Colniza, no Estado de Mato Grosso, faz parte do "Cinturão Verde da Amazônia", região pertencente à área de Floresta Tropical. 0 referido município foi emancipado em 1998, de área territorial que pertencia ao município de Aripuanã, MT. A economia da região era baseada em atividade predominantemente extrativista vegetal e de minério. Com objetivo de ocupação da Região Amazôni$\mathrm{ca}$, inicialmente a área desse município foi colonizada por agricultores vindos principalmente do Rio Grande do Sul na década de 90 . Devido às dificuldades de infra-estrutura ocorreu grande evasão destes produtores. A partir de 1994 ocorreu um novo fluxo migratório, principalmente de produtores oriundos dos estados de Rondônia e Espírito Santo, havendo apropriação de terras devolutas com formação de grandes fazendas ocasionando a expansão da pecuária local.

No entanto, os produtores relatam que um dos principais limitantes da continuidade dessa expansão é a ocorrência de "morte súbita" de bovinos, que é descrita como a principal causa de perdas econômicas. Há relatos de que os bovinos oriundos de outros municípios, onde não ocorrem históricos de mortes súbitas, são mais afetados que aqueles já adaptados à região. Em visitas às propriedades e em vistorias nas pastagens onde ocorriam as mortes súbitas, notamos a coincidência da presença de Amorimia pubiflora nas pastagens com os históricos de "mortes súbitas". Vários produtores do município, principalmente os que têm propriedades no local denominado Linha 24 e entorno, relataram a ocorrência de mortes. Um deles anotou que em um rebanho de 1.000 bovinos, em 2009 morreram 80 bovinos, em 2010 morreram 41 bovinos e em 2011 morreram 61 bovinos (18,2\% de mortalidade em 3 anos). Outro relatou que de uma compra de 110 bovinos de outro município, 60 morreram (54,5\%) após 15 dias da introdução, durante um manejo para vacinação. Outro produtor descreveu as mortes de 40 entre 120 bovinos que estavam em um pasto, durante a movimentação para transporte ao frigorífico.

Enquanto na primeira visita havia histórico de que vários produtores combatiam diversas plantas, algumas similares as do gênero Amorimia, outros combatiam plantas lactescentes, sem que se notassem resultados. Já nas últimas visitas constatamos que a maioria dos pecuaristas e dos vaqueiros tem conhecimento sobre a toxicidade e distinguem facilmente A. pubiflora, que é localmente conhecida como "suma," de outras plantas que não tem importância para pecuária local. Os pecuaristas são unânimes em mencionar a dificuldade para erradicar ou controlar essa planta, que a arrancam do pasto com uso de enxadão ou aplicação de 
herbicidas, misturados ou não com óleo diesel; porém esses métodos não são muito eficazes, pois há intenso rebrote após 15 a 30 dias. Alguns produtores comentam que essas técnicas devem ser repetidas, pois periodicamente ocorre a rebrota da planta.

As mortes ocorrem independentes da disponibilidade de forragem, pois nas propriedades visitadas as pastagens para os bovinos (predominantemente Brachiaria spp. e $\mathrm{Pa}$ nicum maximum) eram abundantes, no entanto é frequentemente relatado que as mortes se concentram principalmente no final do período da seca e início do período de chuva, coincidindo com maior quantidade de brotação de A. pubiflora. Os produtores relatam que ocasionalmente os bovinos são encontrados já mortos, mas a maioria morre durante a movimentação, após apresentarem agressividade, tremores musculares, instabilidade postural, relutância em se movimentar, decúbito ou queda repentina. Alguns produtores descrevem, ainda, que os bovinos "dão pulos repentinos", caem ao solo e morrem em poucos minutos. Há relato de aproveitamento para o consumo quando os bovinos são imediatamente sangrados.

Durante nossas visitas em uma propriedade ocorreu a movimentação de um lote para manejo e um bovino morreu, com comportamento agressivo, relutância a movimentação, incoordenação, queda e morte com evolução de 15 minutos. Este bovino foi necropsiado sem que se notassem alterações macro ou microscópicas significativas.

\section{Acompanhamento clínico experimental}

Nos animais que morreram, as primeiras manifestações clínicas foram observadas entre 34min (Ovino 20) e 17h34min (Ovino 162) após a administração da planta, a evolução clínica foi de 3 min (Ovino 162) a 15h20min (Ovino 8), e o tempo decorrido desde a administração da planta até a morte dos ovinos foi de 13h36min (Ovino 166) a 20h25min (Ovino 8). o quadro clínico (Quadro 2) foi similar na maioria dos ovinos; a taquicardia foi uma das primeiras alterações, seguido de evidenciação da jugular, tremores musculares, além de apatia e ocasional relutância à movimentação. Todos os sinais se acentuavam após a movimentação.

Em 7 ovinos $(8,14,17,22,156,162$, e 166), dos 12 que morreram com diferentes doses tóxicas de A. pubiflora, foi observado uma fase final superaguda, na qual havia, durante ou logo após a movimentação, relutância para caminhar, cifose, tremores e contrações musculares generalizadas, principalmente de membros, cabeça e pescoço; os ovinos apresentavam ainda, marcada taquipneia com respiração abdominal, por vezes com boca aberta, ficavam em decúbito esternal e logo lateral ou caíam diretamente em decúbito lateral, com contrações musculares, seguidas por opistótono, nistagmo, vocalização, cianose de mucosa oral e morte. Cinco ovinos $(20,25,163,165$ e 169) foram encontrados mortos, no máximo 1 hora após a última observação clínica.

Dentre os ovinos que se recuperaram, o Ovino 21 manifestou tremores musculares, taquicardia, instabilidade, relutância para se movimentar e cegueira (andava a esmo, batia em obstáculos e não tinha reflexo palpebral) e recuperou-se após curso clínico de 122h20min. O Ovino 50, que recebeu $2 \mathrm{~g} / \mathrm{kg}$, manifestou leve aumento da frequência cardíaca durante a movimentação até 48 horas após a administração; recuperou-se posteriormente. 0 Ovino 23, que recebeu a dose de 1,5g/kg, apresentou leve taquicardia com 100 batimentos por minuto (bpm) quando em repouso e até 238 bpm após movimentação por período de 50 horas; recuperou-se em seguida. No Ovino 164 notou-se taquicardia com 200 bpm e recuperou-se 48h depois da administração. 0 Ovino 168 apresentou andar rígido e recuperou-se 86h27min após. 0 Ovino 167 tinha a jugular ingurgitada, pulso venoso, ficou em decúbito esternal, decúbito lateral e apresentou melhora clínica em $48 \mathrm{~h}$.

0 Bovino 1, que tinha comportamento linfático, consumiu espontaneamente $2 \mathrm{~g} / \mathrm{kg}$ de folhas jovens de $A$. $p u$ biflora, apresentou taquicardia (80 bpm) 24 horas após a administração da planta, e antes da movimentação. Após 3 minutos de movimentação, notou-se jugular ingurgitada e

Quadro 2. Principais alterações clínicas em ovinos intoxicados experimentalmente com Amoroimia pubiflora

\begin{tabular}{|c|c|c|c|c|c|c|c|c|c|c|c|c|c|c|c|c|}
\hline \multirow{2}{*}{$\begin{array}{c}\text { Ovino } \\
\text { no. }\end{array}$} & \multirow{2}{*}{$\begin{array}{l}\text { Dose } \\
\mathrm{g} / \mathrm{kg}\end{array}$} & \multicolumn{15}{|c|}{ Sinais clínicos ${ }^{\mathrm{a}}$} \\
\hline & & Apatia & $\begin{array}{l}\text { Jugular in- } \\
\text { gurgitada }\end{array}$ & $\begin{array}{c}\text { Pulso } \\
\text { venoso }\end{array}$ & $\begin{array}{l}\text { Decúbito } \\
\text { esternal }\end{array}$ & $\begin{array}{c}\text { Decúbito } \\
\text { lateral }\end{array}$ & $\begin{array}{l}\text { Arritmia } \\
\text { cardíaca }\end{array}$ & Dispneia & $\begin{array}{l}\text { Taqui- T } \\
\text { cardia }\end{array}$ & Tremores & $\begin{array}{l}\text { Incoor- } \\
\text { denação }\end{array}$ & Cifose & $\begin{array}{l}\text { Andar } \\
\text { rígido }\end{array}$ & $\begin{array}{c}\text { Trismo man } \\
\text { dibular }\end{array}$ & & $\begin{array}{l}\text { nose Desfecho } \\
\text { clínico }^{\mathrm{b}}\end{array}$ \\
\hline 8 & 5 & + & + & + & + & + & - & + & + & + & - & - & - & - & & M \\
\hline 20 & 5 & + & + & + & + & - & - & - & + & - & - & - & - & - & & M \\
\hline 14 & 3 & - & + & + & + & + & - & - & + & + & - & - & - & - & & M \\
\hline 25 & 3 & + & - & - & + & - & - & + & + & - & - & - & - & - & & M \\
\hline 22 & 2 & + & + & + & + & + & - & + & + & + & - & - & - & - & & M \\
\hline 21 & 2 & + & + & + & + & - & + & + & + & + & + & - & + & + & & $\mathrm{R}$ \\
\hline 50 & 2 & - & - & - & + & - & - & - & + & - & - & - & - & - & & $\mathrm{R}$ \\
\hline 23 & 1,5 & - & - & - & - & - & - & - & + & - & - & - & - & - & & $\mathrm{R}$ \\
\hline 162 & 5 & - & - & - & + & - & - & - & + & - & - & - & - & - & & M \\
\hline 17 & 5 & + & + & + & + & - & - & - & + & - & - & + & + & - & & M \\
\hline 156 & 4 & + & + & + & - & - & - & + & + & - & + & + & + & - & & M \\
\hline 163 & 3 & - & - & - & - & - & - & - & + & - & - & - & - & - & & M \\
\hline 165 & 3 & + & - & - & + & - & - & - & + & - & - & - & + & - & & M \\
\hline 164 & 2 & - & - & - & - & - & - & - & + & - & - & - & - & - & & $\mathrm{R}$ \\
\hline 166 & 20 & + & - & - & + & - & + & - & + & - & - & - & + & - & & M \\
\hline 168 & 15 & - & - & - & - & - & - & - & + & - & - & - & + & - & & $\mathrm{R}$ \\
\hline 167 & 10 & - & + & + & + & + & - & - & + & - & - & - & - & - & & $\mathrm{R}$ \\
\hline 169 & 5 & - & - & - & - & - & - & - & + & - & - & - & - & - & & M \\
\hline
\end{tabular}

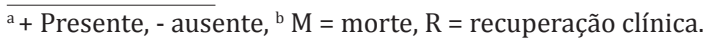


marcada relutância em se movimentar; permaneceu imóvel mesmo quando tangido com uso de cavalo. A frequência cardíaca elevou-se para 180-200 bpm. Este quadro se repetiu por mais de 24 horas; posteriormente, notou-se que a frequência cardíaca permanecia, quando em repouso, dentro da normalidade e havia leve alteração (100-120 bpm) quando o bovino era tangido.

O Bovino 2 que, tinha comportamento agressivo, recebeu, por via oral forçada, $3 \mathrm{~g} / \mathrm{kg}$ de folhas jovens de $A$. $p u$ biflora. Após 7 horas da administração da planta estava em pé e pastejava no piquete onde foi solto, alerta e aparentemente sem alterações clínicas; após 1 minuto de trote caiu de súbito, teve fortes espasmos musculares e movimentos de pedalagem, tremores musculares e opistótono (Fig.2). Notou-se marcado ingurgitamento e pulso jugular, taquicardia $(220 \mathrm{bpm})$ e taquipneia $(60 \mathrm{mpm})$. Após 2 minutos nesta posição, levantou-se e começou a correr, porém com tremores musculares intensos e instabilidade postural; trotou por 30 segundos e caiu novamente; repetiu-se o quadro anterior com frequência cardíaca de 300 bpm. Isso se repetiu por mais duas vezes, e na última vez ficou deitado por aproximadamente 30 minutos. Após $22 \mathrm{~h}$ da administração estava em pé no piquete com pulso jugular evidente e após curta movimentação (30") caiu ao solo, teve fortes contrações musculares, principalmente dos membros, opistótono, nistagmo, vocalizou e morreu 6 minutos após a queda.

\section{Achados de necropsia}

Observou-se nos Ovinos 8, 14, 20, 22 e 25 que o pulmão estava aumentado de volume, com petéquias e equimoses na cavidade pleural, leve edema interlobular e ao corte apresentava-se mosqueado com áreas avermelhadas. Notou-se, ainda, grande quantidade de espuma brancacenta ou com leve tom róseo na traqueia; folhas inteiras ou parcialmente digeridas de $A$. pubiflora foram observadas no rúmen. Observaram-se mucosas avermelhadas no abomaso e intestino e no rim ao corte havia petéquias multifocais, principalmente na região cortico-medular. Nas cavidades torácica e pericárdica havia discreta deposição de líquido amarelo-citrino. Petéquias e equimoses ocasionais foram observadas no pericárdio, pleura, meninges e intestino. $\mathrm{Na}$ necropsia do Bovino 2 e na dos Ovinos 17, 156, 162, 163, 165, 166 e 169 não foram encontradas alterações macroscópicas significativas.

\section{Achados histopatológicos}

Os principais achados histológicos foram observados no rim e eram de tumefação e vacuolização (degeneração hidrópico-vacuolar) e cariopicnose em células epiteliais dos túbulos uriníferos contorcidos classificada como leve nos Ovinos 8, 20, 22, 25, 162 e 169, moderada nos Ovinos 156 e 166 e acentuada no Bovino 2. Adicionalmente, havia hemorragias de serosas, edema e congestão pulmonar, con-

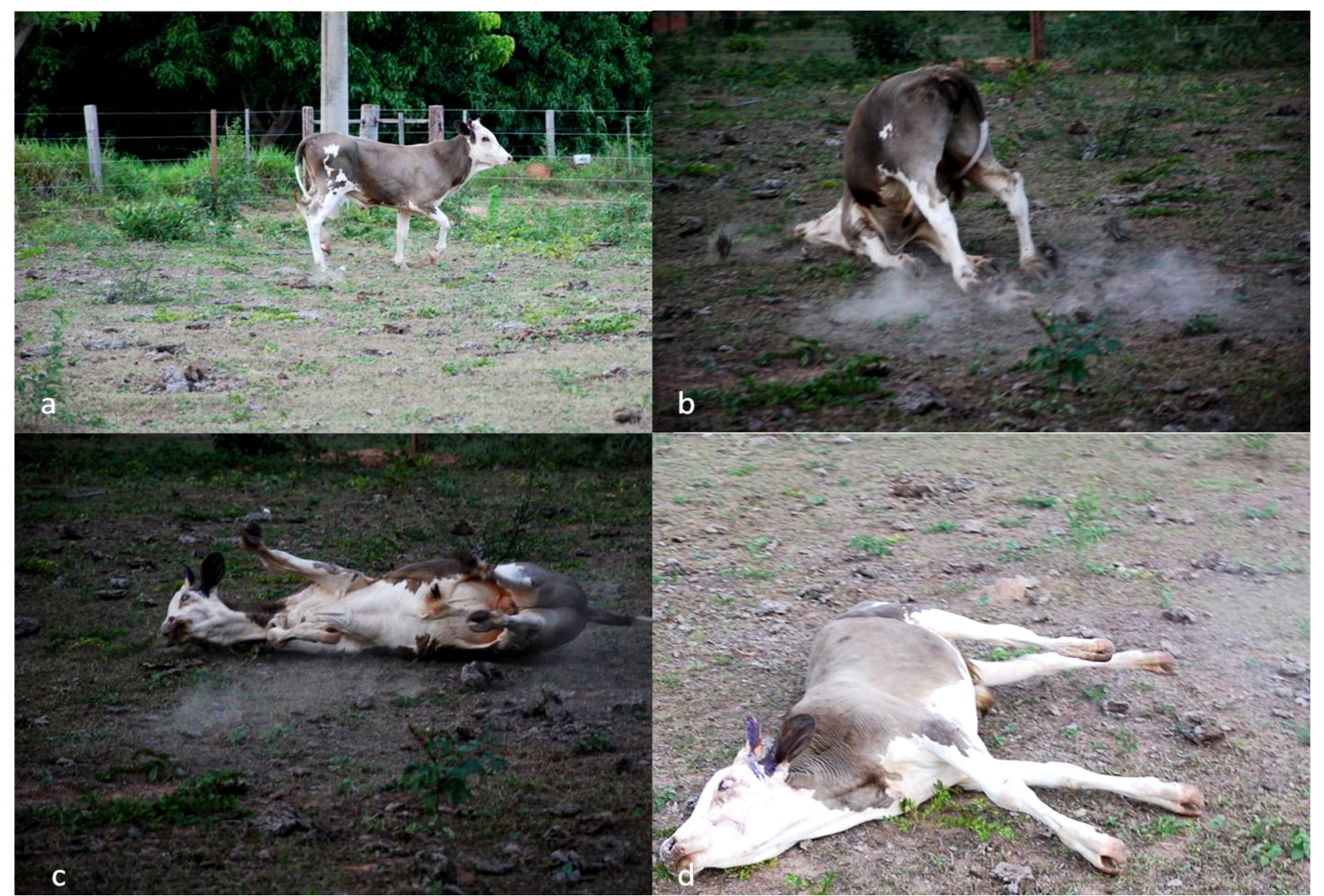

Fig.2. Sequência do quadro clíncio que ocorreu durante a movimentação de bovino experimentalmente intoxicado por folhas de Amoirimia pubiflora. (a) Dismetria, (b) queda brusca, (c) decúbito lateral, (d) opstotono e movimentos de pedalagem. 
gestão principalmente da medular do rim, e de sinusoides hepáticos em variável intensidade nos Ovinos 8, 14, 20, 22 e 25.

\section{Princípio tóxico}

Foi detectado 0,015\% de monofluoracetato de sódio nas folhas jovens de A. pubiflora, coletadas em novembro de 2011.

\section{DISCUSSÃO}

As informações obtidas durante os inquéritos sobre a ocorrência de "morte súbita" associada ao consumo de Amorimia pubiflora no município de Colniza, MT dão conta de que essa é a principal causa de perdas econômicas para a pecuária local, não só em decorrência das mortes de bovinos, fato que por si só já é significativo, pois afeta, sob algumas condições, até $50 \%$ do rebanho ou do lote, como também porque a planta é de difícil controle, o que onera sobremaneira o sistema produtivo. A remoção manual ou química da planta nos pastos não tem se mostrado eficaz, e portanto, necessita de manejos sistemáticos. 0 uso de corte mecânico com enxadão (usado em pequenas áreas) e a capina química (independente do princípio ativo ou da marca comercial do herbicida utilizados) devem ser repetidas várias vezes em uma área para que se obtenha resultado favorável, e mesmo assim deve ser mantida constante vigilância, pois A. pubiflora possui raiz axial profunda, o que predispõe a rebrota. 0 uso de cercas para isolar as áreas afetadas não é aplicável, porque a planta está bem difundida por todas as pastagens. Os produtores afirmam que cuidados durante o manejo, evitando a movimentação, diminuem significativamente a mortalidade (abaixo de 3\% durante o ano), porém algumas situações inevitáveis, tais como vacinações obrigatórias e movimentação para as vendas dos bovinos, causam estresse e, portanto, precipitam a morte dos animais.

No Brasil, até o momento, outras 12 espécies de plantas são conhecidas por causarem morte súbita: Palicourea marcgravii, P. aeneofusca, $P$. juruana, $P$. grandiflora, Tanaecium (Arrabidaea) bilabiatum, Fridericia (Arrabidaea) japurensis, Pseudocalymma elegans, Amorimia rigida, A. exotropica, Amorimia sp. (que inclue M. aff. rigida) (Tokarnia et al. 2012, Lee et al. 2012), A. septentrionalis e Mascagnia sepium (acredita-se tratar Amorimia (Mascagnia) amazônica) (Lee et al. 2012). A região de Colniza também é área de ocorrência de Palicourea marcgravii (cafezinho, erva-de-rato), que não foi encontrada nas propriedades visitadas.

Os vaqueiros e os proprietários informam que as mortes ocorrem principalmente no final da seca e no início das chuvas (set.-dez.). Essa informação vai ao encontro de nossas observações e experimentos, que apontaram a folhas jovens como mais tóxicas. A brotação pode ocorrer durante quase todo ano, pelo crescimento vegetativo da planta ou quando provocada pela movimentação mecânica do solo e exposição do sistema radicular da planta. No final das secas há menor disponibilidade de pastagem, o que faz com que os bovinos consumam maior quantidade de brotos de A. pubiflora. A palatabilidade da planta é percebida tanto pela observação a campo, quando se nota que os bovinos consomem principalmente as folhas jovens de brotações, como a constatação durante os experimentos, nos quais a planta era rapidamente consumida pelos bovinos e ovinos sem a necessidade de forçar a administração.

Tokarnia \& Döbereiner (1973) descreveram variação de toxidez de A. pubiflora. Em abril/maio do ano de 1973 a dose letal da planta em brotação, floração e frutificação, foi de $5 \mathrm{~g} / \mathrm{kg}$; no final da época de chuva, com as folhas maduras, ela situou-se em torno de $20 \mathrm{~g} / \mathrm{kg}$. Constatamos em nossos estudos, que folhas jovens tendem a ser até 10 vezes mais tóxicas do que as maduras independentemente da época de coleta. A administração de $2 \mathrm{~g} / \mathrm{kg}$ de folhas jovens causou quadro clínico em todos os ovinos, bem como em um bovino; a morte ocorreu somente em um ovino que ingeriu esta dose, após a movimentação. Todos os ovinos e o bovino que receberam $3 \mathrm{~g} / \mathrm{kg}$, morreram. As folhas maduras e frutos de A. pubiflora foram tóxicas para ovinos nas doses de $20 \mathrm{~g} / \mathrm{kg}$ e $5 \mathrm{~g} / \mathrm{kg}$, respectivamente.

Foi detectado, em amostras de folhas jovens de A. pubiflora coletadas durante a segunda visita, $0,015 \%$ de monofluoracetato, diferindo do descrito por Lee et al. (2012) que demonstrou $0,006 \%$ em amostras analisadas em 2010, mas que foram coletadas durante a primeira visita em 2004; essas amostras ficaram arquivadas no University of Michigan Herbarium, porém sabe-se que há perda da toxicidade de $A$. pubiflora se guardada por um período superior a um mês (Tokarnia et al. 2012). Foi detectado em folhas de A. septentrionalis $0.002 \pm 0.0009 \%$ de MFA. Amostras de Palicourea marcgravii de Goiás e São Paulo continham $0.24 \pm 0.10 \%$ e $0.21 \pm 0.17 \%$ de MFA, respectivamente (Lee et al 2012). Nestes termos, apesar do número reduzido de amostras coletadas, há um indicador da relação entre quantidade de MFA e toxicidade da planta com consequente mortes de animais.

No município de Colniza a espécie bovina é a mais afetada pela ocorrência de "mortes súbitas" por A. pubiflora, semelhante com o que ocorre em outras regiões (Tokarnia et al. 2012). Alguns produtores relataram mortes repentinas de equídeos, mas não encontramos evidências para essa afirmação, pois não foram feitos exames para confirmação do diagnóstico. Não são conhecidas intoxicações naturais e não encontramos na literatura, trabalhos com intoxicação experimental por essa planta em ovinos. A ovinocultura nas propriedades que visitamos não tem expressão econômica, mas a presença da planta pode ser um fator negativo para uma expansão dessa criação na região.

Experimentalmente, as alterações clínicas podem ser divididas em duas fases; a inicial com manifestações menos acentuadas e geralmente de duração mais longa e outra, superaguda, finalizando com a morte do animal, de poucos minutos. Inicialmente observaram-se taquicardia, relutância a movimentação, tremores, apatia, decúbito esternal, ingurgitamento e pulso jugular; este quadro era precipitado principalmente pela movimentação. 0 quadro superagudo era caracterizado por relutância para caminhar, cifose, tremores e contrações musculares generalizadas, marcada taquipneia, respiração abdominal, por vezes com a boca aberta, decúbito esternal e rapidamente lateral ou quedas diretamente em decúbito lateral, opstótono, nistagmo, vo- 
calização, cianose de mucosa oral e, por fim, a morte. Esta fase superaguda é importante para caracterizar clinicamente o diagnóstico, e é frequentemente a mais observada por quem está envolvido no manejo dos bovinos. A informação de que alguns bovinos já são encontrados mortos, está de acordo com o que se observa nas intoxicações por outras plantas que causam a "morte súbita" (Tokarnia et al. 2012) e por MFA (Peixoto et al. 2010). Alguns ovinos destes experimentos foram encontrados mortos sem que se observassem sinais clínicos.

Neste experimento, 8 ovinos apresentaram lesão renal de intensidade de leve a moderada, um bovino apresentou lesão renal acentuada e 4 ovinos não evidenciaram lesões renais. No estudo com intoxicação por MFA todos os ovinos (Peixoto et al. 2010) e todos os bovinos (Nogueira et al. 2010) apresentaram degeneração hidrópico-vacuolar dos túbulos uriníferos contorcidos distais, corroborando com a importância diagnóstica dessa lesão (Tokarnia et al. 2012). Degeneração hidrópico-vacuolar ocorreu em 66\% dos ovinos e no bovino que morreu intoxicado por $A$. pubiflora neste estudo. Não é uma alteração específica, mas é um importante achado diagnóstico em animais intoxicados por plantas que contém MFA (Döbereiner \& Tokarnia 1959, Tokarnia \& Döbereiner 1986, Tokarnia et al. 1993, 2012, Barbosa et al. 2003, Oliveira et al. 2004, Helayel et al. 2009). Revisão abrangente sobre esta alteração é apresentada por Nogueira et al. $(2010,2011)$.

Relatos de que os bovinos oriundos de regiões onde não ocorre "morte súbita" são mais susceptíveis à intoxicação, pode ser um indicativo de que os animais se tornam resistentes ao consumo de plantas que contém monofluoracetato. Esta possibilidade está relacionada com a degradação por enzimas de microorganismos que contém fluoroacetato-dehydrogenase ${ }_{2}$ e que quebra a ligação do carbono-flúor (Fetzner \& Lingens 1994). Vários microorganismos que degradam MFA foram isolados de solo na Austrália (Twigg \& Socha 2001) e de solo (Camboim et al. 2012a) e ambiente ruminal (Pimentel 2011, Camboim et al. 2012b) no Brasil. Essa observação pode indicar um promissor método de controle desta intoxicação ao se estabelecer a possibilidade de detoxificação ruminal de monofluoracetato.

0 nome popular "suma" usado para A. pubiflora na região é incomum para a espécie em outras regiões. As denominações "suma-branca" e "suma-roxa" são usadas para designar A. rigida, no vale do rio Doce nos estados de Minas Gerais e do Espírito Santo. Como na colonização do município há participação de produtores desses estados, acreditamos que estes tenham difundido este termo.

Agradecimentos.- Ao Instituto Nacional de Ciências e Tecnologia para Controle de Intoxicações por Plantas (Proc. 0573534-2008-0) pelo financiamento deste projeto, ao Dr William R. Anderson pela identificação botânica.

\section{REFERÊNCIAS}

Anderson W.R. 2006. Eight segregates from the neotropical genus Mascagnia (Malpighiaceae). Novon 16(2):168-204.
Barbosa J.D., Oliveira C.M.C., Tokarnia C.H. \& Riet-Correa F. 2003. Comparação da sensibilidade de bovinos e búfalos à intoxicação por Palicourea marcgravii (Rubiaceae). Pesq. Vet. Bras. 23(4):167-172.

Camboim K.A., Tadra-Sfeir M.Z., Souza E.M., Pedrosa F.O., Andrade P.P., McSweeney C.S. \& Riet-Correa F. \& Melo M.A. 2012a. Defluorination of sodium fluoroacetate by bacteria from soil and plants in Brazil. Scientific World Journal 2012:149893.

Camboim K.A., Almeida A.P., Tadra-Sfeir M.Z., Junior F.G., Andrade P.P., McSweeney C.S., Melo M.A. \& Riet-Correa F. 2012b. Isolation and identification of sodium fluoroacetate degrading bactéria from caprine rumen in Brazil. Scientific World Journal 2012:178254.

Döbereiner J. \& Tokarnia C.H. 1959. Intoxicação de bovinos pela "erva-de-rato" (Palicourea marcgravii St. Hil.) no vale do Itapicuru, Maranhão. Arqs Inst. Biol. Anim., Rio de J., 2:83-91

Fetzner S. \& Lingens F. 1994. Bacterial Dehalogenases: Biochemistry, Genetics, and Biotechnological Applications. Microbiol. Rev. 58(4):641685.

Helayel M.A., França T.N., Seixas J.N., Nogueira V.A., Caldas S.A. \& Peixoto P.V. 2009. Morte súbita em bovinos causada pela ingestão de Pseudocalymma elegans (Bignoniaceae) no município de Rio Bonito, RJ. Pesq. Vet. Bras. 29(7):498-508.

Lee S.T., Cook D., Riet-Correa F., Pfister J.A., Anderson W.R., Lima F.G. \& Gardner D.R. 2012. Detection of monofluoroacetato in Palicourea and Amorimia species. Toxicon 60:791-796.

Lemos R.A.A., Guimarães E.B., Carvalho N.M., Nogueira A.P.A., Santos B.S., Souza R.I.C., Cardinal S.G. \& Kassab H.O. 2011. Plant poisonings in Mato Grosso do Sul, p.68-72. In: Riet-Correa F., Pfister J., Schild A.L. \& Wierenga T. (Eds), Poisoning by Plants, Mycotoxins, and Related Toxins. CAB International, Wallingford, UK.

Mamede M.C.H. 2010. Amorimia in Lista de Espécies da Flora do Brasil. Disponível em <http://floradobrasil.jbrj.gov.br/2010/FB101438> Acesso em 6 fev. 2013.

Nogueira V.A., França T.N., Peixoto T.C., Caldas S.A., Armién A.G. \& Peixoto P.V. 2010. Intoxicação experimental por monofluoroacetato de sódio em bovinos: aspectos clínicos e patológicos. Pesq. Vet. Bras. 30(7):533540 .

Nogueira V.A., Peixoto T.C., França T.N., Caldas S.A. \& Peixoto P.V. 2011. Intoxicação por monofluoroacetato em animais. Pesq. Vet. Bras. 31(10):823838.

Oliveira C.M.C., Barbosa J.D., Macedo R.S.C., Brito M.F., Peixoto P.V. \& Tokarnia C.H. 2004. Estudo comparativo da toxidez de Palicourea juruana (Rubiaceae) para búfalos e bovinos. Pesq. Vet. Bras. 24(1):27-30.

Peixoto T.C., Nogueira V.A., Coelho C.D., Veiga C.C.P., Peixoto P.V. \& Brito M.F. 2010. Avaliações clínico-patológicas e laboratoriais da intoxicação experimental por monofluoroacetato de sódio em ovinos. Pesq. Vet. Bras. 30(10):1021-1030.

Pimentel M.F.A. 2011. Isolamento e identificação de microrganismo resistente ao fluoroacetato de sódio. Dissertação de Mestrado, Faculdade de Agronomia, Medicina Veterinária e Zootecnia, Universidade Federal de Mato Grosso, Cuiabá. 42p.

Tokarnia C.H. \& Döbereiner J. 1973. Intoxicação por Mascagnia pubiflora em bovinos no Estado de Mato Grosso. Pesq. Agropec. Bras. 8:61-68.

Tokarnia C.H. \& Döbereiner J. 1986. Intoxicação por Palicourea marcgravii (Rubiaceae) em bovinos no Brasil. Pesq. Vet. Bras. 6(3):73-78.

Tokarnia C.H., Costa E.R., Barbosa J.D., Armién A.G. \& Peixoto P.V. 1993. Intoxicação experimental por Palicourea marcgravii (Rubiaceae) em eqüinos. Pesq. Vet. Bras. 13(3/4):67-72.

Tokarnia C.H., Brito M.F., Barbosa J.D., Peixoto P.V. \& Döbereiner J. 2012. Plantas Tóxicas do Brasil. 2 ${ }^{\mathrm{a}}$ Ed. Editora Helianthus, Rio de Janeiro. 566 .

Twigg L.E. \& Socha L.V. 2001. Defluorination of sodium monofluoroacetate by soil microorganisms from central Australia. Soil Biol. Biochem. $33: 227-234$ 